
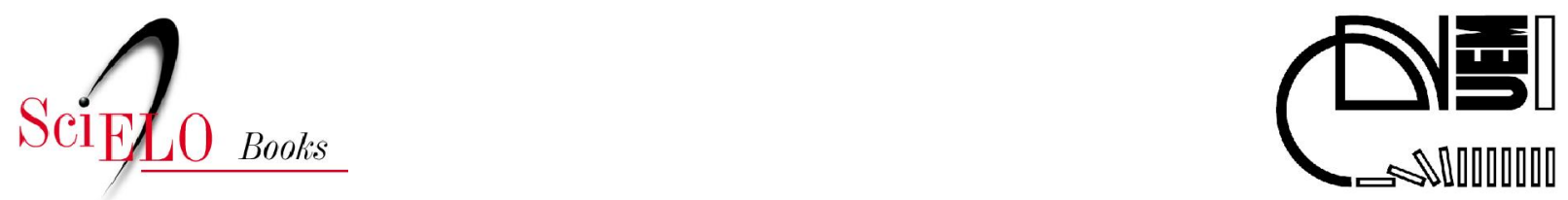

\title{
V. O desenvolvimento da situação do mercado cafeeiro mundial e o significado do International Coffee-Agreement
}

\author{
Paulo Astor Soethe (org.) \\ Daniel Martineschen (coord.) \\ Caio Heleno da Costa Pereira \\ Dionei Mathias \\ Elisete Antoniuk \\ Fernanda Boarin Boechat \\ Frederico Füllgraf \\ Natasha Pereira da Silva \\ Sibele Paulino \\ Sirlene Nair Neubauer \\ (transl.)
}

\section{SciELO Books / SciELO Livros / SciELO Libros}

SOETHE, PA., org. MARTINESCHEN, D., et al., transl. KOHLHEPP, G. IV. O desenvolvimento da situação do mercado cafeeiro mundial e o significado do International Coffee-Agreement. In: Colonização agrária no Norte do Paraná: processos geoeconômicos e sociogeográficos de desenvolvimento de uma zona subtropical do Brasil sob a influência da plantação de café [online]. Maringá: Eduem, 2014, pp. 119-125. ISBN 978-85-7628-655-4. Available from SciELO Books $<$ http://books.scielo.org $>$.

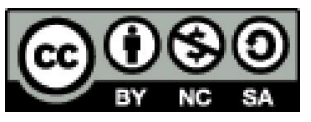

All the contents of this chapter, except where otherwise noted, is licensed under a Creative Commons Attribution-Non Commercial-ShareAlike 3.0 Unported.

Todo o conteúdo deste capítulo, exceto quando houver ressalva, é publicado sob a licença Creative Commons Atribuição Uso Não Comercial - Partilha nos Mesmos Termos 3.0 Não adaptada.

Todo el contenido de este capítulo, excepto donde se indique lo contrario, está bajo licencia de la licencia Creative Commons Reconocimento-NoComercial-CompartirIgual 3.0 Unported. 


\section{O DESENVOLVIMENTO DA SITUAÇÃO DO MERCADO CAFEEIRO MUNDIAL E O SIGNIFICADO DO INTERNATIONAL COFFEE-AGREEMENT ${ }^{241}$}

\section{PROBLEMAS DE ESTABILIZAÇÃO DO MERCADO CAFEEIRO MUNDIAL}

A situação do mercado cafeeiro mundial ao final da Segunda Guerra Mundial foi o resultado de um processo de desenvolvimento complicado, em cujo transcurso a política cafeeira brasileira fez uma tentativa desesperada de manter os preços do mercado mundial através de restrições de plantio e destruindo grandes quantidades de café não-industrializado.

A destruição ${ }^{242}$ de cerca de 70 milhões de sacas de café $(60 \mathrm{~kg})$ no Brasil, entre os anos de 1931 e 1943 , em grande parte provenientes de aquisições de estoques de depósito mas também de novas colheitas de café, levou, no entanto, somente a uma desaceleração da queda de preços. O preço de venda do tipo Santos 4 em Nova York caiu de 9-11 centavos/lb. entre 1931 e 1937 para 7 centavos até o final de 1940, e foi então tabelado oficialmente em 13,4 centavos pelos Estados Unidos até 1945, de modo a reduzir os problemas de orçamento de produtores latino-americanos decorrentes das dificuldades de exportação ocasionadas pela guerra. ${ }^{243}$

Enquanto a safra média brasileira de café caiu de 24,5 milhões de sacas no começo dos anos 1930 para 14,4 milhões de sacas por volta do final da Segunda Guerra Mundial, as colheitas de café na Colômbia cresceram nesse período com um aumento contínuo de $50 \%$, enquanto a produção de café na América Central permaneceu quase a mesma. A Indonésia sumiu totalmente do mercado mundial em consequência da invasão japonesa; em comparação com isso, a produção de café na África triplicou!

No total, o balanço do mercado mundial mostrou, na média quinquenal, entre 1928/29 até 1933/34 e entre 1940/41 até 1945/46, uma redução da produção exportável de café por volta de 7-8 milhões de sacas.

A uma breve fase mundial de esgotamento após o término das negociações bélicas seguiu-se um forte aumento do consumo de café, sobretudo nos EUA. O produção de café refreada por décadas logo já não pôde mais suprir o crescimento surpreendentemente rápido do consumo de café, especialmente porque o potencial de consumo europeu começava a se recuperar. O déficit, no entanto, pôde ser suprido no primeiro momento por meio dos 6 milhões de sacas ainda existentes ao final da Guerra nos estoques de depósito brasileiros até seu esgotamento, em 1949 (ROWE, 1963, p. 13-14).

No Brasil, sobretudo em São Paulo, a mais importante área de produção de então, o plantio de café depois da Segunda Guerra Mundial a princípio só voltou a crescer relativamente devagar, especialmente porque os plantadores reagiram - após 15 anos de preços baixos, interdição de novos plantios (salvo Paraná) e destruição de colheitas - de maneira hesitante à situação do mercado mundial e à valorização do café.

A repentina escassez de café, que surgia pela primeira vez depois de duas décadas e depois de consumir totalmente os estoques que encobriam a verdadeira situação, causou uma subida de preço de 50\% no tipo Santos 4 de 1949 a 1950: de 33 centavos a 50,5 centavos/lb. ${ }^{244}$ Após alguns anos de estabilização dos preços de café, os preços explodiram em decorrência de notícias sobre os vastos

241 Tradução de Dionei Mathias e Natasha Pereira da Silva.

242 A maior parte foi queimada nas áreas de produção, afundada no mar ou também usada como combustível nas locomotivas. Quantidades menores serviram para a produção de adubo e produtos sucedâneos (DAMBAUGH, 1959, p. 42).

243 A estabilização do comércio de café no Ocidente durante a Segunda Guerra Mundial foi garantida pelo Inter-American Coffee Agreement (1940-1948), inspirado pelo desejo dos EUA de consolidar o apoio às forças aliadas por parte dos 14 países exportadores de café das América Latina (FREDERICK, 1970, p. 25).

244 Preços para Santos 4 na Bolsa de café de Nova York na média anual/em centavos/lb.: 1946: 18,7; 1947/48: 26 - 27; 1949: 33; (ROWE, 1963, p. 14). 
prejuízos decorrentes de geadas na segunda metade do ano de 1953 nas regiões brasileiras de plantio de café; Santos 4 alcançou em 1954 sua mais alta média mensal de 88 centavos! ${ }^{245}$

As oscilações de preço na Bolsa de café de Nova York mostram claramente uma dependência direta das condições brasileiras que influenciavam decisivamente a situação geral:

Se o aumento de preço do café em 1950 no Brasil já havia levado a uma expansão dos cafezais, agora, em 1954, o boom do preço do grão teve como efeito uma expansão das plantações cafeeiras até então desconhecida, ${ }^{246}$ sobretudo nas regiões pioneiras do Paraná (ver Cap. IV, 1b), e isso apesar do risco de geadas.

Como a perda da colheita por causa da geada de 1953 acabou sendo menor do que se temia ${ }^{247}$ e o ano de 1955 - por meio da regeneração dos cafeeiros atingidos pela geada como também através das plantações amanhadas no início dos anos 1950 que começavam a produzir - trouxe uma colheita especialmente grande (Figura 2), os preços do café voltaram a cair rapidamente (Figura 5).

A forte geada de 1955 nos estado do Paraná e São Paulo surtiu um aumento dos preços do mercado mundial das 'arábicas' colombianas, enquanto as variedades brasileiras mesmas aumentaram pouco. Apesar da subsequente queda abrupta dos preços do café por causa da oferta elevada, as plantações de café no Brasil, sobretudo no âmbito da exploração do Noroeste paranaense, mas também na África e em outros países da América do Sul e Central, continuaram a ser expandidas até o final dos anos 50 ( Figura 2).

Figura 5: Desenvolvimento de preços de determinados tipos de café

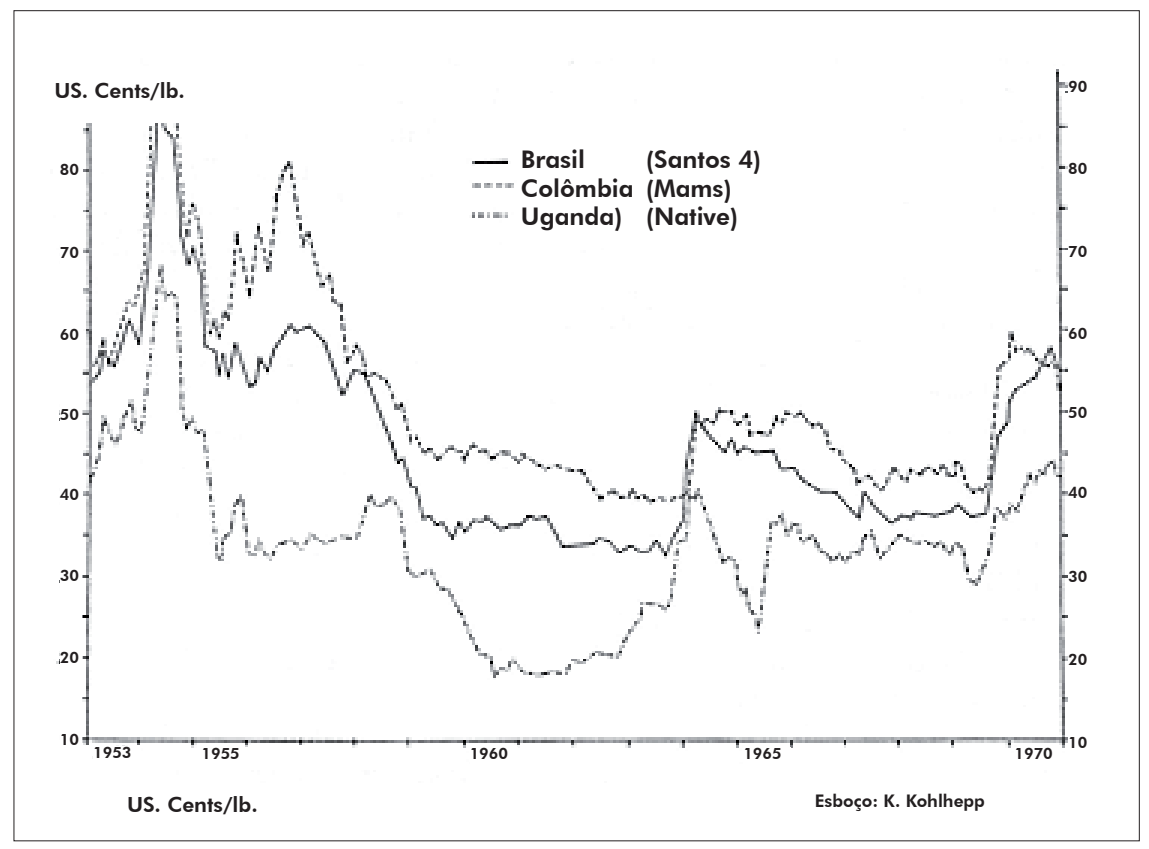

245 Ver Figura 5 de acordo com dados em: IBC, Anuário Estatístico do Café, 1968/70.

246 A quantidade de pés de café no Brasil cresceu de 2.337 milhões de árvores em 1950 para 3.865 milhões (1958/59), e só no Paraná cresceu, no mesmo período, de 233 a 1.141 milhões (Figura 2).

247 No Brasil, muitas vezes prejuízos relativamente pequenos ocasionados por geadas nas regiões de plantio de café foram dramatizados por parte dos plantadores e dos órgãos de controle regionais para conseguir empréstimos e subvenções.

No comércio internacional de café, notícias de geadas oriundas do Brasil aumentavam a exportação através de compras preventivas por parte dos países consumidores mais importantes. 
Quando em 1957 novamente sérios problemas de excedente por parte dos principais países produtores voltavam a acossar o comércio internacional de café, fortaleceu-se a tendência geral de um acordo multilateral no mercado cafeeiro mundial.

\section{TENTATIVAS INTERNACIONAIS DE COORDENAÇÃO E FUNDAMENTOS DO ICA}

Os esforços unilaterais de décadas por parte do Brasil para tabelar os preços de café não haviam surtido efeito. Tampouco as Conferências Cafeeiras em Sevilha (1929), São Paulo (1931), Bogotá (1936), Havana (1937), Nova York (1940) e Washington (1940) levaram a acordos internacionais, com exceção do Interamerican Coffee Agreement ocasionado pela guerra. ${ }^{248}$ Foi somente o Pacto da Cidade do México de 1957 que originou um acordo suprarregional diante da delicada situação cafeeira mundial: Brasil, Colômbia, Costa Rica, El Salvador, Guatemala, México acordaram a fixação de cotas de exportação.

Em 1958 essa convenção se estendeu para um Latin-American Coffee Agreement [Acordo Latinoamericano do Café], com a adesão de 15 nações. A partir disso, desenvolveu-se em 1959 uma convenção internacional, na qual o Brasil, dentre outros países, aceitou um controle da exportação e do transporte do café para os portos de exportação, e, como todo país produtor de café, deveria reter futuramente como reserva $20 \%$ da média do café exportado entre 1957 e 1958. A França e Portugal tornaram-se membros por causa das colônias africanas, a Inglaterra e a Bélgica garantiram uma restrição da exportação de suas colônias africanas com base na convenção. Quando o Reino Unido tornou-se efetivamente membro em 1960, na convenção, que foi prorrogada em 1960 e 1961 por um ano, estava associada cerca de $90 \%$ da produção mundial de café para a exportação.

Desde 1958, um grupo de pesquisa sobre o café estava encarregado da análise da situação mundial do café, com o objetivo de redigir uma convenção internacional a longo prazo. A Coffee Federation of the Americas (FEDECAME) ${ }^{249}$ - que representava os tipos de café ameno das regiões elevadas e o Brasils - e a Inter-African Coffee Organisation (I.A.C.O.) - fundada no final de 1960 e porta-voz das 'robustas' - funcionavam como representações regionais de interesse no círculo inflexível em torno da solução do problema dos excedentes da produção de café.

O desenvolvimento da constelação política no hemisfério ocidental por meio da presença comunista em Cuba deu um impulso decisivo para a conclusão da convenção internacional do café.

Depois do presidente Kennedy ter anunciado a 'Aliança para o Progresso' em março de 1961, os EUA acentuaram, na Conferência dos Estados Americanos em Punta Del Este realizada em agosto desse mesmo ano, seu interesse por uma convenção mundial e por uma consolidação dos preços do café, que deveriam reverter sobretudo para a estabilidade econômica e consequentemente para a política da América Latina. O Inter-American Economic and Social Council [Conselho Econômico e Social Interamericano] da Organização dos Estados Americanos resolveram por unanimidade pela proteção de uma convenção de longo prazo sobre o café entre países produtores e consumidores.

248 Com relação ao problema de desenvolvimento dos acordos internacionais sobre o comércio de café, v. entre outros: Pan American Coffee Bureau (1959); Silveira (1963); Dambaugh (1959); King (1962); Rowe (1963); Faraco e Borio (1964); Lazzarini (1967); Krug e Poerck (1968); Frederick (1970); The song is ended - but what of the International Coffee Agreement? (1970); IBC, Anuário Estatístico do Café (1968-1970).

249 Paralelamente a isso, o chamado Mexican Club - que compreendia os sete estados-membros do acordo de 1957 da Cidade do México - também realizou alguns encontros (ROWE, 1963, p. 17). 
Tabela 22: A importância econômica da exportação do café em países selecionados (1963)

\begin{tabular}{|l|c|c|}
\hline Ranking segundo grau de dependência & $\begin{array}{c}\text { Receita da exportação de café } \\
\text { (em US\$ 1.000) }\end{array}$ & \begin{tabular}{c} 
Parcela no PIB do país (\%) \\
\hline 1. Colômbia
\end{tabular} 303.006 \\
\hline 2. Brasil & 756.951 & 53,9 \\
\hline 3. Uganda & 76.200 & 52,8 \\
\hline 4. Guatemala & 77.075 & 51,2 \\
\hline 5. Etiópia & 44.360 & 49,6 \\
\hline 6. Costa Rica & 45.328 & 47,7 \\
\hline 7. El Salvador & 71.400 & 46,4 \\
\hline 8. Portugal & 68.660 & 41,9 \\
\hline 9. Burundi (inclusive Ruanda) & 5.534 & 40,9 \\
\hline 10. Costa do Marfim & 99.000 & 38,8 \\
\hline Para comparar: México & 52.259 & 5,6
\end{tabular}

Fonte: IBC, Anuário Estatístico do Café (1968-1970, p. 79) e ICA - Doc. ED (418/69).

De modo análogo ao que ocorreu com o Inter-American Agreement de 1940 (determinado pela guerra), o engajamento americano para a realização do International Coffee Agreement [Acordo Internacional do Café - ICA] em 1962 tinha uma relevância geopolítica devido à crescente crise cubana e à infiltração comunista acentuada na América Latina - temida pelos EUA - no caso de uma eventual crise na economia do café.

A Tabela 22 oferece um panorama do grau da dependência econômica de alguns países da América Latina e da África pela exportação do café.

A dependência do comércio de café dos estados latino-americanos em relação ao potencial de consumo dos EUA tornou-se especialmente significativa no exemplo brasileiro:

Tabela 23: A relação de dependência entre o Brasil e os EUA na economia do café ao tempo do acordo do ICA

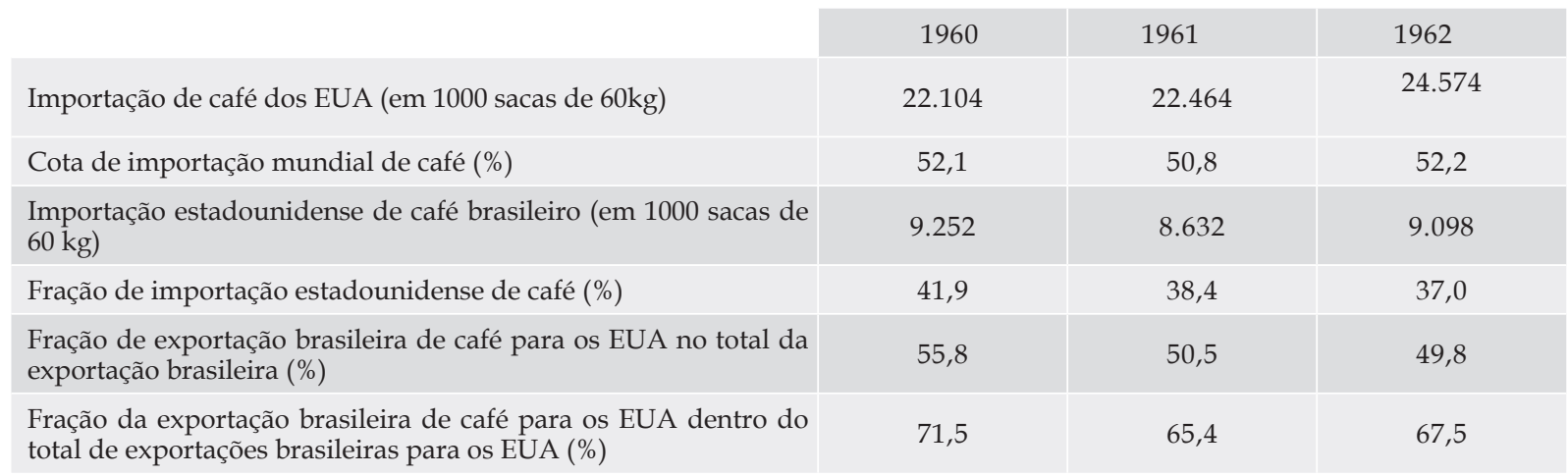

Fonte: IBC, Anuário Estatístico do Café (1968-1970).

A metade da exportação de café do Brasil era destinada aos EUA, cuja fração correspondia a mais de $50 \%$ ao total de importação mundial de café. A fração brasileira de café importado pelos EUA diminuiu um pouco entre os anos de 1960 e 1962. Em 1962, o café ainda ocupava cerca de 2/3 do valor de exportação do comércio brasileiro aos EUA. 
O projeto da ICA, modificado depois da recusa do Brasil e de outros países a uma internacionalização de estoques de café, foi aprovado em 1962 pela United Nations Coffee Conference [Conferência das Nações Unidas para o Café] em Nova Iorque. O acordo, válido por 5 anos, entrou em vigência em 1963, e no mesmo ano a Organização Mundial do Café, à qual pertencem os 34 países de exportação e os 22 de importação, estabeleceu suas atividades em Londres.

Resumidamente, as bases do International Coffee Agreement são as seguintes:

1. Acordo multilateral para ajuste de produção e consumo durante a ocorrência do convênio a longo prazo.

2. Estabilidade do preço com base no preço do café no ano de 1962 no mínimo.

3. Controle centralizado de exportação e regulação de importação.

4. Aumento contínuo do consumo de café e eliminação dos entraves de tributos de importação.

5. Redução dos excedentes de café dos principais países produtores por responsabilidade própria pela medida encontrada.

6. Proteção dos países produtores de café através de segurança das vagas de trabalho, melhores salários e uma melhor qualidade de vida.

A estipulação de cotas específicas de exportação para todos os países, que venderam mais de 100.000 sacas de café nos mercados principais nos EUA e na Europa foi a principal medida do ICA. A 30 dias do começo de cada ano do café, são estimadas a exportação de café e a importação do ano que se inicia. Depois disso, são determinadas as cotas por uma complicada fórmula de distribuição.

O enorme crescimento da produção mundial de café desde 1957 foi resultado sobretudo da expansão dos cafeeiros na região pioneira do Norte do Paraná desde o começo dos anos 50. Para evitar a queda do preço do café a um patamar muito baixo, o Brasil recorreu ao método de estocar a quantidade excedente. Com isso, por um lado o rendimento da exportação de café foi mantido, por outro, a decadência financeira de muitos produtores de café em São Paulo, sul de Minas Gerais, Espírito Santo - estados que trabalhavam com custos elevados - foi reduzida com a existência de cafeeiros antigos e menos produtivos.

No âmbito internacional, uma queda de preço pôde ser evitada. Por meio de acordos internacionais, o preço se manteve em média em 35 cts/lb., entre a metade de 1959 até 1962 (Figura 5).

Do outro lado, os estoques de café no Brasil até 1962 cresciam em torno de 55 milhões de sacas (Figura 6), isto é, o triplo de um ano de exportação médio do Brasil ou, ainda, mais que o consumo anual de café (1961: 44 milhões de sacas). No Brasil, as cotas de crescimento anuais previstas dos estoques de café verde foram estimadas em cerca de 10 milhões de sacas.

Nessa situação de excedente, a forte geada de 1962 no Paraná só poderia ter trazido uma redução temporária da pressão.

Para o cumprimento dos acordos firmados, a destruição ao menos dos cafeeiros antigos e menos produtivos revelou-se como solução do problema do café, tanto interno quanto em nível internacional ${ }^{250}$.

O boom do café no Paraná - cuja fração alcançou 30\% da produção mundial em 1962 e 1963 indicava a necessidade de se fechar um acordo internacional do café (Tabela 24).

O papel dominante do Brasil na economia mundial de café como produtor (1962/1963: 47\% _Tabela 24) e a dependência das relações de preço da produção do país exigiram do Brasil, tanto nas regiões de cultivo antigas quanto nas regiões mais jovens e inadequadas ecologicamente, medidas de restrição decisivas, que foram realizadas em dois programas de grande alcance para destruir as árvores de café e que assim provocaram mudanças decisivas na paisagem agrária, bem como transformações na estrutura agrária.em sua infraestrutura.

250 Além disso, exigiu-se a destruição dos estoques brasileiros e colombianos, bem como recomendou-se uma redução extrema do preço, de modo a cessar o boom do cultivo de café e promover espontaneamente a destruição dos cafeeiros não rentáveis. A perda do rendimento que surgiu através da baixa quantidade de exportação deveria substituir o café de países produtores (ROWE, 1963, p. 198 e 199). 
Figura 6: Área de cultivo, produção, exportação e estoques de café do Brasil entre 1960 e 1972

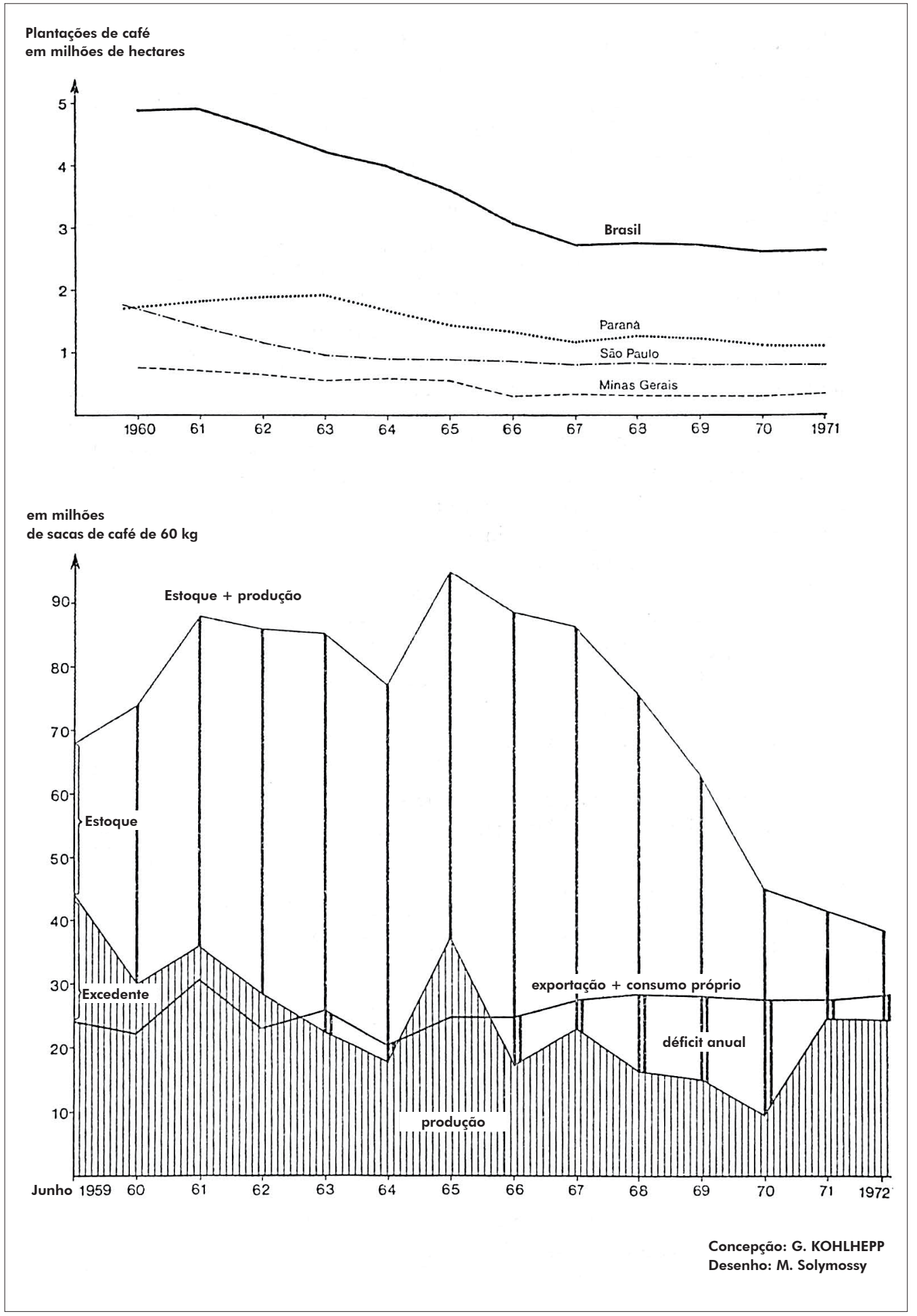

Fonte: IBC, Anuários Estatísticos do Café, 1965-1972 
Tabela 24: Produção de café mundial do tipo exportação.

Situação antes e no início do ICA (em 1.000 sacas de 60kg)

\begin{tabular}{|c|c|c|c|c|c|}
\hline Ranking & & $1960-61$ & $1961-62$ & $1962-63$ & $1962-63$ \\
\hline Total mundial & & 60.407 & 68.748 & 61.577 & 100,0 \\
\hline Membros do ICA & & 60.227 & 68.468 & 61.455 & 99,8 \\
\hline 1. Brasil & $(\mathrm{C})$ & 29.800 & 39.600 & 28.900 & 47,0 \\
\hline 2. Colômbia & $(\mathrm{A})$ & 7.000 & 6.800 & 6.500 & 10,6 \\
\hline 3. Costa do Marfim & (D) & 3.150 & 1.600 & 3.300 & 5,4 \\
\hline 4. Angola & (D) & 2.700 & 2.750 & 3.050 & 5,0 \\
\hline 5. Uganda & (D) & 1.895 & 1.933 & 2.930 & 4,8 \\
\hline 6. Indonésia & (D) & 1.600 & 1.650 & 2.080 & 3,4 \\
\hline 7. Guatemala & (B) & 1.300 & 1.500 & 1.700 & 2,8 \\
\hline 8. Salvador & (B) & 1.350 & 1.800 & 1.540 & 2,5 \\
\hline 9. México & (B) & 1.450 & 1.500 & 1.250 & 2,0 \\
\hline 10. Etiópia & (C) & 960 & 1.100 & 1.150 & 1,9 \\
\hline 11. Costa Rica & (B) & 1.050 & 1.025 & 930 & 1,5 \\
\hline \multirow[t]{2}{*}{ 12. Congo (Kinshasa) } & (D) & 850 & 850 & 1.050 & 1,7 \\
\hline & & & & & demais: 11,4 \\
\hline Arábicas & & 48.064 & 57.765 & $46 . S 54$ & 76,2 \\
\hline A suaves columbianos & & 8.030 & 7.695 & 7.570 & 12,3 \\
\hline B outras arábicas suaves & & 8.378 & 9.370 & 9.234 & 15,0 \\
\hline C arábicas não-lavadas & & 31.656 & 40.700 & 30.050 & 48,9 \\
\hline D Robustas & & 12.163 & 10.703 & 14.601 & 23,8 \\
\hline comparar: Paraná (C) & & 14.320 & 17.942 & 18.032 & 29,3 \\
\hline
\end{tabular}

Fonte: IBC, Anuário Estatístico do Café (1968-70); Pan American Coffee Bureau. 